Int. J. Morphol.,

32(3):798-802, 2014.

\title{
Evaluation of the Vertebral Artery by 3D Digital Subtraction Angiography
}

\author{
Evaluación de la Arteria Vertebral Mediante Angiografía por Sustracción Digital 3D
}

\author{
Hasan Tetiker*; Mehmet Çimen** \& Mehmet Ilkay Kosar*
}

TETIKER, H; CIMEN, M. \& KOSAR, M. I. Evaluation of the vertebral artery by 3D digital subtraction angiography. Int. J. Morphol., 32(3):798-802, 2014.

SUMMARY: The objective of the present study is to determine origin, entry level to the transverse foramen and diameter according to sex and side through 3D angiographic images of seventy-nine vertebral arteries obtained using DSA imaging method. During radiological evaluation, axial, coronal and sagittal images of the artery were used. Data of our study was uploaded to SPSS 14.0 program and significance test and Mann Whitney-U test of the difference between two means were used to evaluate the data. While 76 of the vertebral arteries $(96.2 \%)$ were originating from the subclavian artery, 3 of them (3.8\%) were directly originating from aortic arch. In 67 of 76 the vertebral arteries originating from the subclavian artery were entering through C6, 6 through $\mathrm{C} 7,2$ through $\mathrm{C} 5$ and one through $\mathrm{C} 4$ transverse foramen. It was seen that one of 3 the vertebral artery originating from aortic arch was entering through C6, one through $\mathrm{C} 7$ and the other through C4 transverse foramen. While the mean diameter of the vertebral artery was $3.88 \pm 0.71 \mathrm{~mm}$ at the right side (3.99 $\mathrm{mm}$ in men, $3.66 \mathrm{~mm}$ in women), the mean diameter at the left side was $4.15 \pm 1.05 \mathrm{~mm}(4.23 \mathrm{~mm}$ in men, $4.06 \mathrm{~mm}$ in women).

KEY WORDS: Vertebral artery; Transverse foramen; Digital subtraction angiography.

\section{INTRODUCTION}

The vertebral artery (VA) originates as the first branch of the first piece of the subclavian artery at the base of the neck. The two VAs have different widths; that is, the one at the left is generally thicker than the right one (Moore et al., 2010). The VA originates from the subclavian artery, travels through the space in pyramid shape between anterior scalene and longus colli muscles, and then it generally reaches transverse foramen of the sixth cervical vertebra. The section up to this part of the artery is called as pars prevertebralis or V1 segment. After this point, the artery raises inside transverse foramen of cervical vertebra at a higher point one after another and then it comes to the upper side of transverse foramen of the atlas. This section is called pars transversaria or V2 segment. After the VA comes out of transverse foramen of the atlas, it travels horizontally, inclines posteriorly and medially and perforates dura mater around the foramen magnum. This section between atlas and the foramen magnum is called suboccipital segment or
V3 segment. The artery travels through subaracnoidal interval at cranial cavity and makes up basilar artery by combining with the opposing the VA at the bottom level of pons. This is the final part of artery and called intracranial segment or V4 segment.

Damage to the VA may lead to decrease in feeding of the posterior cranial fossa which includes cerebellum and brain stem. In such case, it may lead to severe neurologic deficits, loss of consciousness and sometimes respiratory and cardiovascular disorder. Therefore, importance of protecting the VA has been emphasized by many authors (Gupta, 2008; Cacciola et al., 2004; Bloch \& Danziger, 1977; Kiresi et al., 2009; Abd el-Bary et al., 1995; Rhoton, 2000). Various methods can be used to display the VA. The imaging methods include magnetic resonance angiography (MRA), computed tomography angiography (CTA), digital subtraction angiography (DSA) and positron emission

\footnotetext{
* Department of Anatomy, Mugla Sitki Kocman University, Faculty of Medicine, Mugla, Turkey.

*** Department of Anatomy, Cumhuriyet University, Faculty of Medicine, Sivas, Turkey.
} 
tomography (PET). Although all non-invasive imaging techniques are being used today, DSA continues to be a gold standard in diagnosis of cerebrovascular, carotid, abdominal aorta and extremity artery pathologies. Furthermore, digital subtraction angiography has priorities over conventional angiography such as traumatizing the patient and applying beam less by using a smaller catheter and lesser contrast substance.

In this study, we aimed to determine origin, entry level to transverse foramen and diameter according to sex and side through 3D angiographic images of seventy nine VA obtained using DSA imaging method.

\section{MATERIAL AND METHOD}

Our study was performed prospectively with 79 cases ( 3 bilateral, 73 unilateral) aged between 28 and 85 (mean 64.22 \pm 3.48 ) who applied to Radiology Department of Cumhuriyet University Research and Practice Hospital between September 2008 and December 2009 after report of local ethics committee had been obtained. Those which were suitable for examining anatomy and morphology of the VA among 3D angiographies obtained from the department were used. The images were divided into groups: sex (female-male) and side (right-left).

The cases were applied selective vertebral artery DSA operation with femoral artery catheterization in supine position. During the operation, a catheter of $5 \mathrm{~F}(1.7 \mathrm{~mm})$ was used and $9 \mathrm{ml}$ non-ionic contrast substance was injected into the artery. Radiologic evaluation was performed using
2006 modal DSA device (Innova 3100, GE Medical Systems, France). In all cases, Matrix: 1280*1024, slice thickness: $0.7 \mathrm{~mm}$ images were obtained. In the evaluation, axial, coronal and sagittal images of the artery were used.

The images were evaluated on Innova Digital Color LCD Monitor (19 inch, flat). The vessel which VA originates from and level of entry to the transverse foramen were determined using the images. Diameter of VA was measured in V2 and V3 segment (sulcus for vertebral artery).

Data of our study was uploaded to SPSS 14.0 program and significance test and Mann Whitney-U test of the difference between two means were used to evaluate the data. The data was expressed in arithmetic mean (X), standard deviation (S), number (n) and percentage (\%) of individuals in the tables and statistical significance was accepted as $\mathrm{p}<0.05$.

\section{RESULTS}

In our study, totally 79 VA angiographies were evaluated. While 76 of VAs (96.2\%) were originating from the subclavian artery, 3 of them $(3.8 \%)$ were directly originating from the aortic arch. Distribution according to sex and side is shown in Table I.

While 68 of 79 VAs $(86.1 \%)$ were entering through transverse foramen of C6 vertebra which is the normal entry point, the others $(13.9 \%)$ were entering through the transverse foramen of a different cervical vertebra (Table II).

Table I. Point of origin of the vertebral artery according to sex and side.

\begin{tabular}{lccccc}
\hline \multirow{2}{*}{ Sex } & \multirow{2}{*}{ Side } & & \multicolumn{2}{c}{ Origin } & \multirow{2}{*}{ Total } \\
\cline { 4 - 5 } & & & Subclavian artery & Aortic arch & \\
\hline \multirow{2}{*}{ Male } & Right & $\mathrm{n}$ & 10 & 0 & 10 \\
& Left & $\mathrm{n}$ & 30 & 3 & 33 \\
\multirow{2}{*}{ Female } & Right & $\mathrm{n}$ & 5 & 0 & 5 \\
\multirow{2}{*}{ Total } & Left & $\mathrm{n}$ & 31 & 0 & 31 \\
& & $\mathrm{n}$ & $76(96,2 \%)$ & $3(3,8 \%)$ & $79(100 \%)$ \\
\hline
\end{tabular}

Table II. Level of entry of the vertebral artery to the transvers foramen according to sex and side.

\begin{tabular}{lccccc}
\hline \multirow{2}{*}{ Sex } & Side & & \multicolumn{2}{c}{ Origin } & \multirow{2}{*}{ Total } \\
\cline { 4 - 5 } & & & Subclavian artery & Aortic arch & \\
\hline \multirow{2}{*}{ Male } & Right & $\mathrm{n}$ & 10 & 0 & 10 \\
& Left & $\mathrm{n}$ & 30 & 3 & 33 \\
\multirow{2}{*}{ Female } & Right & $\mathrm{n}$ & 5 & 0 & 5 \\
\multirow{2}{*}{ Total } & Left & $\mathrm{n}$ & 31 & 0 & 31 \\
& & $\mathrm{n}$ & $76(96,2 \%)$ & $3(3,8 \%)$ & $79(100 \%)$ \\
\hline
\end{tabular}


Table III. Level of entry of the vertebral artery into transverse foramen according to its origin.

\begin{tabular}{lccc}
\hline Level & Side & \multicolumn{2}{c}{ Origin } \\
\cline { 3 - 4 } & & $\begin{array}{c}\text { Aortic } \\
\text { arch }\end{array}$ & $\begin{array}{c}\text { Subclavian } \\
\text { artery }\end{array}$ \\
\hline C4 & Right & 0 & 0 \\
& Left & 1 & 1 \\
C5 & Right & 0 & 1 \\
& Left & 0 & 1 \\
C6 & Right & 0 & 15 \\
& Left & 1 & 52 \\
C7 & Right & 0 & 1 \\
& Left & 1 & 5 \\
\hline
\end{tabular}

According to origin, levels of entry of the VA into transverse foramen are as follows (Table III). Both of the two VAs entering into transverse foramen from $\mathrm{C} 4$ level was left-sided, and while one of them was originating from aortic arch, the other from the subclavian artery (Figs. 1-3).

While the mean diameter of the VA was $3.88 \pm 0.71$ $\mathrm{mm}$ at the right side ( $3.99 \mathrm{~mm}$ in men, $3.66 \mathrm{~mm}$ in women), the mean diameter at the left side was $4.15 \pm 1.05 \mathrm{~mm}(4.23$ $\mathrm{mm}$ in men, $4.06 \mathrm{~mm}$ in women). When right and left artery diameters were compared, the difference between the sides was found insignificant $(\mathrm{p}>0.05)$.

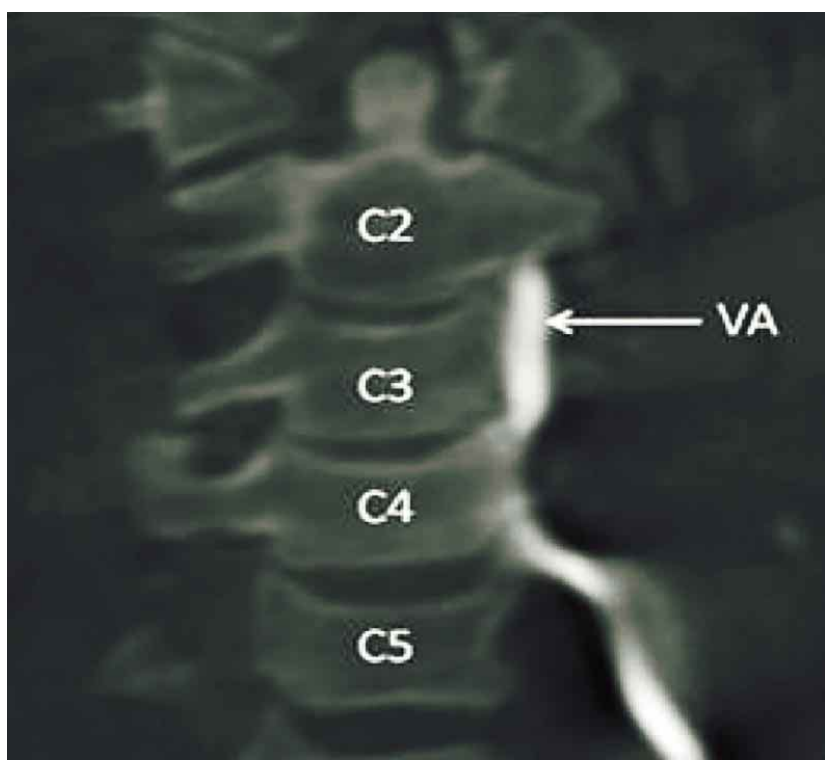

Fig. 1. Entry of left the vertebral artery into $\mathrm{C} 4$ transverse foramen on coronal plan. C2: axis, C3: third cervical vertebra, C4: fourth cervical vertebra, C5: fifth cervical vertebra VA: vertebral artery.

\section{DISCUSSION}

The brain gets blood support from two main arterial systems. Internal carotid arteries are located anteriorly and

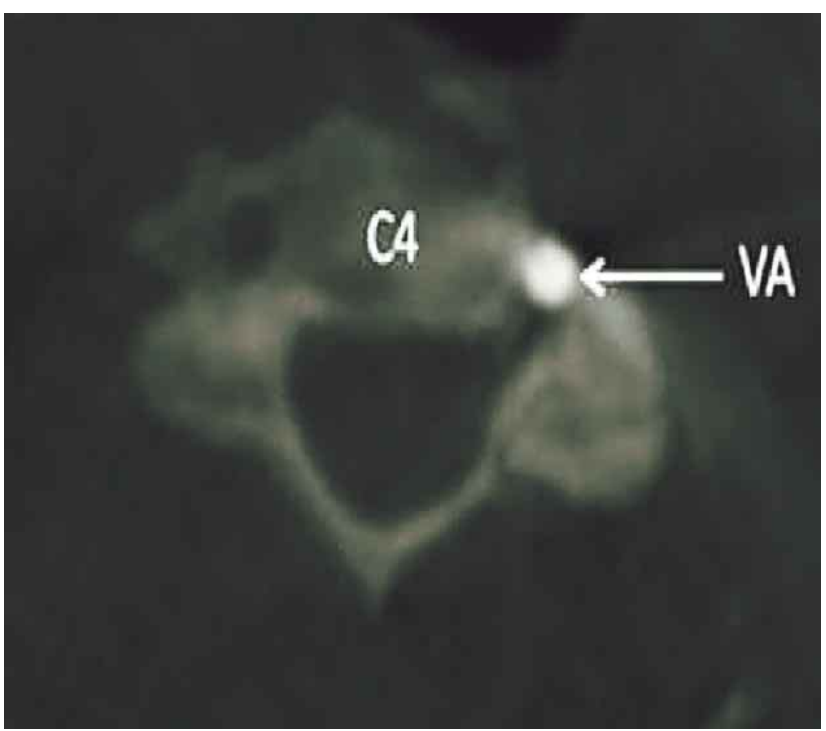

Fig. 2. Left vertebral artery inside transverse foramen on axial slice at corpus level of C4. C4: fourth cervical vertebra, VA: vertebral artery.

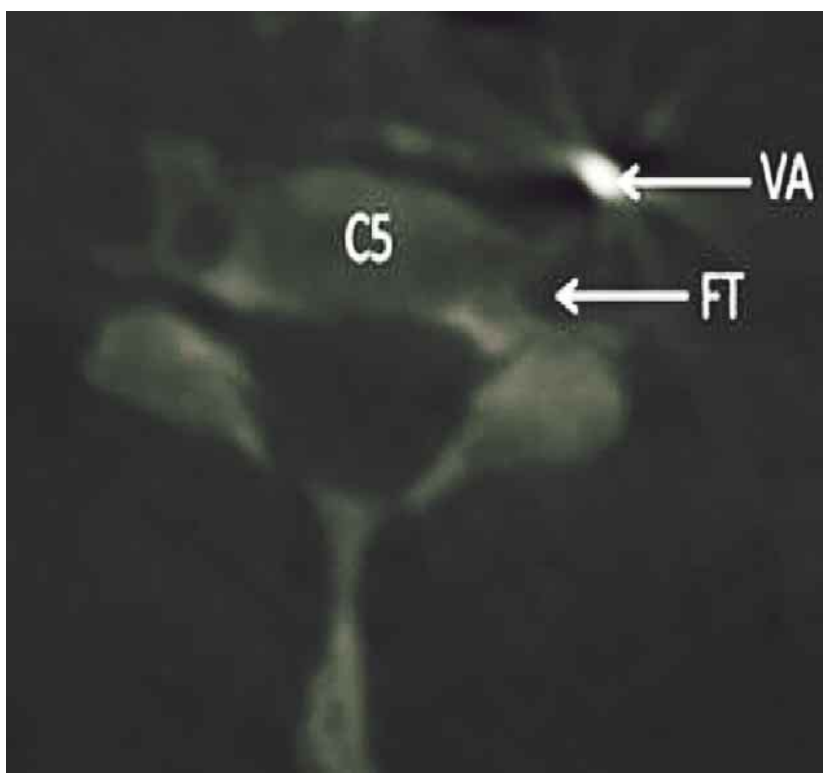

Fig. 3. Travel of the vertebral artery outside transverse foramen on axial slice at corpus level of C5. , C5: fifth cervical vertebra, FT: transverse foramen of the fifth cervical vertebra, VA: the vertebral artery.

vertebrobasilar system is located posteriorly. Vertebrobasilar system feeds spinal cord, brain stem, cerebellum and inferior and posterior part of cerebrum (occipital and temporal lobes). In our study, the origin, entry level to the transverse foramen and the diameter of the VA were determined on 3D angiographic images according to sex and side.

Origin. The VA is the first and thickest branch of the subclavian artery originating from neck base. The VA may 
originate from another artery as a variation (Tuncer et al., 2010). These abnormal origins result from persistence of dorsal intersegmental arteries located more cranially than the seventh of intersegmental arteries during embryologic period. This is the most common origin anomaly. If one of the upper (the first or second) cervical intersegmental arteries persist, the VA originates from internal carotid artery or external carotid artery. If involutional disorder happens in one of the lower (fourth, fifth or sixth) cervical intersegmental arteries, the VA originates from aortic arch at the left side or from common carotid artery on both sides. Bifid originated VA variation happens when two intersegmental arteries persists.

The most common origin anomaly of the VA is that it directly originates from the aortic arch (Uflacker, 2007; Bloch \& Danziger). In the literature, there are publications notifying that the VA originates not only from aortic arch but also from common carotid artery, internal carotid artery, external carotid artery and thyrocervical trunk or as a second branch of the subclavian artery (Higashi et al., 2008; Strub et al., 2006; Goray et al., 2005; Cheng et al., 2009). Moreover, bifid originated anomalies have also been notified (Suzuki et al., 1978; Sugita et al., 1995). In such case, the artery does generally have double origins: one from the subclavian artery and the other from the aortic arch.

Origin anomaly of the left VA is more common than origin anomaly of right VA (Uflacker; Bloch \& Danziger). When the left VA originates from the aortic arch, its most common localization is between left common carotid artery and left subclavian artery and incidence of this anomaly varies between 2,4-5.8\% in the literature (Uflacker; Lemke et al., 1999; Komiyama, et al., 2001; Muralimohan et al., 2009). Less frequently (less than 1\%), the left VA has bifid origin. In less than $1 \%$ of general population, the left VA sometimes emerges as the fourth branch of the aortic arch (after the left subclavian artery) (Saadoon, 1991). The other origin anomalies of the left VA is that it originates from left common carotid artery, left inferior thyroid artery or external carotid artery. The last mentioned three variational cases are seen very rarely (Uflacker; Bloch \& Danziger). While 64 left VA used in our study were separating from the left subclavian artery which is the normal point of origin as the first branch at the rate of $95.3 \%$, it was separating as directly the third branch of the aortic arch showing origin variation at the rate of $4.7 \%$ (between left common carotid artery and left subclavian artery).

Incidence of origin anomaly in the right VA is lower than the left side. Origin anomalies of the right VA are divided into 3 categories: those originating directly from aortic arch, those originating from another artery other than aortic arch, and bifid originated ones. Komiyama et al., in their angiographic study, they didn't find any origin anomalies in the right 717 vertebral arteries. All of 15 right VA used in our study (100\%) were originating from a normal position as the first branch of the right subclavian artery they didn't show any origin variation.

Levels of entry into transverse foramen. The VA frequently enters through transverse foramen of C6 vertebra. On the contrary, the artery can also enter through transverse foramen of the vertebras from C2 to C7 (Lemke et al.; Matula et al., 1997). While 76 of 79 vertebral arteries used in our study are originating from the subclavian artery which is the normal point of origin, 3 of them are originating from aortic arch. 67 of 76 vertebral arteries originating from the subclavian artery are entering through C6, 6 through C7, 2 through $\mathrm{C} 5$ and one through $\mathrm{C} 4$ transverse foramen. It is seen that one of 3 vertebral arteries originating from the aortic arch is entering through $\mathrm{C} 6$, one through $\mathrm{C} 7$ and the other through C4 transverse foramen.

Being aware of entry of the VA into transverse foramen at a different unusual level and paying attention to this situation will help to minimize possible damages to the artery during surgical operations on this region. Especially, bone protection of V1 segment of the VA doesn't exist during lateral operations on this region. Therefore, it will be useful to determine route of the artery before operation in order to prevent undesired iatrogenic complications.

Diameter of the VA. Diameter of the VA is wider in the left than the right. In our study, the mean diameter was $3.88 \pm 0.71$ $\mathrm{mm}$ at the right (Male: 3.99 ; Female: 3.66 ) and $4.15 \pm 1.05$ $\mathrm{mm}$ at the left (Male: 4.23; Female: 4.06). When the diameters were compared in terms of sex and side, the difference was insignificant ( $p>0.05)$. In the literature, the different diameter values between 2 and $2.6 \mathrm{~mm}$ were accepted as threshold value for hypoplasia of the VA (Park et al., 2007; Chen et al., 2010; Perren et al., 2007). Being inspired from the studies mentioned above, we accepted diameter of artery as $\leq 2.5 \mathrm{~mm}$ to determine hypoplasia of the VA. There were 4 cases meeting this criterion and the rate of hypoplasia was $5 \%$.

\section{CONCLUSION}

The VA may be injured during surgical operations due to its complicated anatomic structure and its neighbors and it may lead to severe clinical problems. Therefore, it is very crucial to know anatomic and morphologic properties of the VA and variations of the artery not only for diagnosis practices but also for surgical and intra-arterial operations. 
TETIKER, H; CIMEN, M. \& KOSAR, M. I. Evaluación de la arteria vertebral mediante angiografía por sustracción digital 3D. Int. J. Morphol., 32(3):798-802, 2014.

RESUMEN: El objetivo fue determinar el origen, nivel de entrada y diámetro del foramen transverso, en función del sexo y lado sobre 79 arterias vertebrales a través de imágenes angiográficas 3D utilizando el método de formación de imágenes DSA. Durante la evaluación radiológica, se utilizaron imágenes axiales, coronales y sagitales de la arteria. Los datos se procesaron en el programa SPSS 14.0 con las pruebas U de Mann Whitney y de significancia para evaluar la diferencia entre los datos. Mientras que 76 de las arterias vertebrales (96,2\%) se originaron de la arteria subclavia, 3 de ellas $(3,8 \%)$ lo hicieron directamente desde el arco aórtico. En 67 de 76 arterias vertebrales, se observó el origin en la arteria subclavia a través de C6; 6 a través de C7, 2 a través de C5 y una a través del foramen transverso en C4. El diámetro medio de la arteria vertebral fue $3,88 \pm 0,71 \mathrm{~mm}$ en el lado derecho (3,99 $\mathrm{mm}$ en hombres y $3,66 \mathrm{~mm}$ en mujeres) y en el lado izquierdo fue 4,15 $\pm 1,05 \mathrm{~mm}(4,23 \mathrm{~mm}$ en hombres y $4,06 \mathrm{~mm}$ en hombres).

PALABRAS CLAVE: Arteria vertebral; Foramen transversal; Angiografía por sustracción digital.

\section{REFERENCES}

Abd el-Bary, T. H.; Dujovny, M. \& Ausman, J. I. Microsurgical anatomy of the atlantal part of the vertebral artery. Surg. Neurol., 44(4):392-400, 1995.

Cacciola, F.; Phalke, U. \& Goel, A. Vertebral artery in relationship to C1-C2 vertebrae: an anatomical study. Neurol. India, 52(2):178-84, 2004.

Chen, Y. Y.; Chao, A. C.; Hsu, H. Y; Chung, C. P. \& Hu, H. H. Vertebral artery hypoplasia is associated with a decrease in net vertebral flow volume. Ultrasound Med. Biol., 36(1):38-43, 2010.

Cheng, M.; Xiaodong, X.; Wang, C.; You, C.; Mao, B.; He, M. \& Zhang, C. Two anatomic variations of the vertebral artery in four patients. Ann. Vasc. Surg., 23(5):689.e1-5, 2009.

Bloch, S. \& Danziger, J. Angiographic evaluation of the vertebral artery with special reference to its cervical portion. S. Afr. Med. J., 52(5):170-5, 1977.

Goray, V. B.; Joshi, A. R.; Garg, A.; Merchant, S.; Yadav, B. \& Maheshwari, P. Aortic arch variation: a unique case with anomalous origin of both vertebral arteries as additional branches of the aortic arch distal to left subclavian artery. AJNR Am. J. Neuroradiol., 26(1):93-5, 2005.

Gupta, T. Quantitative anatomy of vertebral artery groove on the posterior arch of atlas in relation to spinal surgical procedures. Surg. Radiol. Anat., 30(3):239-42, 2008.

Higashi, N.; Shimada, H.; Simamura, E. \& Hatta, T. Right vertebral artery as the fourth branch of the aortic arch. Anat. Sci. Int., 83(4):314-8, 2008.

Kiresi, D.; Gumus, S.; Cengiz, S. L. \& Cicekcibasi, A. The morphometric analysis of the $\mathrm{V} 2$ and $\mathrm{V} 3$ segments of the vertebral artery: normal values on MDCT. Comput. Med. Imaging Graph., 33(5):399-407, 2009.

Komiyama, M.; Morikawa, T.; Nakajima, H.; Nishikawa, M. \& Yasui, T. High incidence of arterial dissection associated with left vertebral artery of aortic origin. Neurol. Med. Chir. (Tokyo), 41(1):8-12, 2001.

Lemke, A. J.; Benndorf, G.; Liebig, T. \& Felix, R. Anomalous origin of the right vertebral artery: review of the literature and case report of right vertebral artery origin distal to the left subclavian artery. AJNR Am. J. Neuroradiol., 20(7):1318-21, 1999.

Matula, C.; Trattnig, S.; Tschabitscher, M.; Day, J. D. \& Koos, W. T. The course of the prevertebral segment of the vertebral artery: anatomy and clinical significance. Surg. Neurol., 48(2):125-31, 1997.
Moore, K. L.; Dalley, A. F. \& Agur, A. M. R. Clinically Oriented Anatomy. 6th ed. Philadelphia, Wolters Kluwer/Lippincott Williams \& Wilkins, 2010.

Muralimohan, S.; Pande, A.; Vasudevan, M. C. \& Ramamurthi, R. Suboccipital segment of the vertebral artery: a cadaveric study. Neurol. India, 57(4):447-52, 2009

Park, J. H.; Kim, J. M. \& Roh, J. K. Hypoplastic vertebral artery: frequency and associations with ischaemic stroke territory. J. Neurol. Neurosurg. Psychiatry, 78(9):954-8, 2007.

Perren, F.; Poglia, D.; Landis, T. \& Sztajzel, R. Vertebral artery hypoplasia: a predisposing factor for posterior circulation stroke? Neurology, 68(1):657, 2007.

Rhoton, A. L. Jr. The far-lateral approach and its transcondylar, supracondylar, and paracondylar extensions. Neurosurgery, 47(3 Suppl.):S195-209, 2000.

Saadoon, K. Atlas of normal and variant angiographic anatomy. Philadelphia, Saunders, 1991

Strub, W. M.; Leach, J. L. \& Tomsick, T. A. Left vertebral artery origin from the thyrocervical trunk: a unique vascular variant. A.J.N.R. Am. J. Neuroradiol., 27(5):1155-6, 2006.

Sugita, S.; Abe, T.; Okura, A.; Wantanabe, M. \& Shigemori, M. MRI demonstration of double origin of the left vertebral artery: case note. Neuroradiology, 37(4):295-6, 1995.

Suzuki, S.; Kuwabara, Y.; Hatano, R. \& Iwai, T. Duplicate origin of left vertebral artery. Neuroradiology, 15(1):27-9, 1978.

Tuncer, M C.; Akgül, Y. H. \& Karabulut, Ö. MR angiography ımaging of absence vertebral artery causing of pulsatile tinnitus: a case report. Int. J. Morphol., 28(2):357-63, 2010.

Uflacker, R. Atlas of vascular anatomy: an angiographic approach. Philadelphia, Lippincott Williams \& Wilkins, 2007.

Correspondence to:

Prof. Dr. Hasan Tetiker

Mugla Sitki Kocman School of Medicine

Department of Anatomy

Central Campus, 48000, Mugla

TURKEY

E-mail: hasantetiker@mu.edu.tr

Received: 09-09-2013

Accepted: 03-05-2014 